"Experiential dimensions of TV advertizing: modeling narrative and non-narrative perceptions"

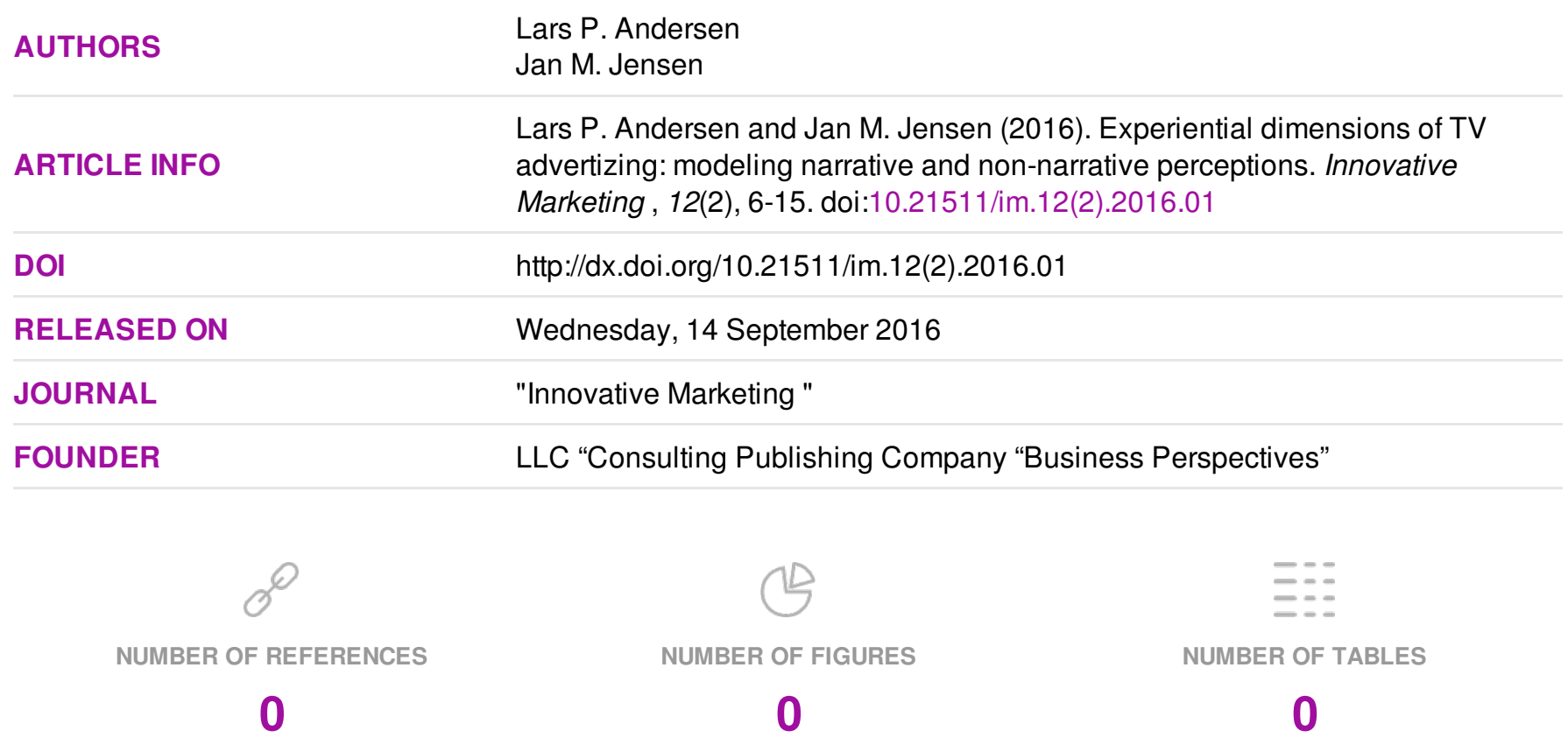

(C) The author(s) 2022. This publication is an open access article. 
Lars P. Andersen (Denmark), Jan M. Jensen (Denmark)

\title{
Experiential dimensions of TV advertizing: modeling narrative and non-narrative perceptions
}

\begin{abstract}
This paper aims at extending advertizing response theory by presenting a three-dimensional model of advertizing perceptions (conceptualized as experiences) by incorporating concepts from cognitive film psychology and narrative transportation theory. The conceptual model is operationalized, tested and evaluated on empirical data from an e-survey measuring the experiential dimensions and ad liking of ten selected TV ads. The findings showed reliability and validity of the proposed measurement scales. The study supported the hypothesized positive influence of all three dimensions on ad liking, but to variable degree. The results showed that the suggested application of the framework is capable of measuring advertizing experiences based on their degree of didactic, narrative and lyrical potential. Findings also suggested that the lyrical dimension supports the narrative experience, adding a new 'lyrical' perspective to the conceptual understanding of narrative transportation in advertizing.
\end{abstract}

Keywords: television advertizing, creative strategy, narrative transportation, advertizing effectiveness, lyrical advertizing, advertizing perceptions.

JEL Classification: M31, M37.

\section{Introduction}

One of the pivotal goals of advertizing research is trying to understand which advertizing 'works best' at generating ad liking, brand recall or recognition, purchase intention or even sales (Van den Putte, 2009; Vakratsasand Ambler, 1999). The execution (message strategy) has been found to be relatively more important in explaining the variance in effects than other factors such as media expenditure (Van den Putte, 2009; Aaker and Carman, 1982), and several large studies have shown ad liking to be an important factor in generating these effects (Haley and Baldinger, 1991; MacKenzie and Lutz, 1989). What remains is how to conceptualize and manage the elements of the advertizing execution along dimensions that are related to the desired effects and strategic objectives. The present paper suggests, develops and tests a three-dimensional model of the advertizing experience by borrowing concepts from cognitive film psychology and narrative transportation theory. In the suggested model, the response measured is considered self-reported advertizing perceptions.

The suggested conceptual framework is an attempt to go beyond isolated studies of 'micro'- or 'midlevel' components of the advertizing execution (visual and verbal signs or functions, e.g., product information, sexual content, rhetorical trope, humour) as called for by Mick et al. (2004) and McQuarrie and Phillips (2008): real persuasive advertizing is more likely to be a result of interactional effects of words and images and

(C) Lars P. Andersen, Jan M. Jensen, 2016.

Lars P. Andersen, Ph.D., Associate Professor, Department of Marketing \& Management, University of Southern Denmark, Odense, Denmark. Jan M. Jensen, Ph.D., Associate Professor, Department of Marketing \& Management, University of Southern Denmark, Odense, Denmark. sounds and story. The approach is also extending narrative transportation theory (Green and Brock, 2000; Green et al., 2004) that considers experiences of narratives to be integrative phenomenon. This also means that potential affective responses are measured indirectly as part of the experience, rather than as a direct measure (e.g., the approach of Batra and Ray, 1986).

The article is organized as follows: first, we begin with a theory section in which we very briefly introduce concepts from cognitive film theory and, then present a three-dimensional conceptual model of advzertizing experience. We, then, suggest hypotheses regarding the dimensions relation to ad liking. Second, a quantitative empirical study is developed, demonstrating a pragmatic application of the framework. The findings are presented and discussed. Finally, managerial implications and directions for future research are discussed.

\section{Theoretical background}

1.1. Conceptual framework and hypotheses. Grodal $(1997,2009)$ presents a cognitive film theory of fiction films, and develops hypotheses of the potential cognitive responses and processes. His 'Typology of Genres of Fiction' is based on 'modes of perception and modes of cognitive and empathic identification with fictive agents' (Grodal, 1997, p. 158). Grodal's prime interest in genre is as prototypical "modes of perception" with distinct contracts of the emotional and cognitive involvement. Grodal's theory is developed for feature films, but can also be applied to video spot advertizing in any media, despite the fact that advertizing is more condensed and directly commercial in purpose. Advertizing has always been relying heavily on the structures and aesthetics of feature films (Stern, 1994), and that advertizing 
imitates art (and vice versa) is not controversial knowledge (Scott, 1994).

Inspired by Grodal, Højbjerg (2000) presents an advertizing typology of three 'modes of representation', including a didactic mode, which Grodal's typology has left out (as he is presenting a theory of the fiction film). The defining characteristics of these modes are closely tied to the experiential dimensions and 'the feeling of being addressed'.

The didactic dimension points to products and brands, ideally with a referentially 'transparent' language that authoritatively and directly informs of problems to be solved, product attributes and benefits (Højbjerg, 2000, Andersen, 2003). The classical types of TV advertizing utilizing the didactic dimension involves presenters (e.g., experts or celebrities) talking directly to camera or use extensive voice over combined with illustrative visuals. These formats are traditionally conceptualized as 'lectures' (Wells, 1988; Deighton et al., 1989) or 'informational' (Rossiter and Percy, 1996) and rely heavily on verbal information and argumentative structure.

The didactic experience is conceptualized as the positive experience of being offered relevant information and arguments: of being 'enlightened', learning something new and interesting. But the pseudoscientific evidence typically presented in advertizing may actually be unsuccessful in generating this experience of learning something new, believable and interesting. This aligns with conventional advertizing strategy for low involvement contexts where ad liking or persuasion is not a prime objective (e.g., Rossiter and Percy, 1996). 'Informational' and 'lecture' formats are related to problem focus and 'negative' motivation (Wells, 1988; Rossiter and Percy, 1996), but the 'negative' experiences that are part of the strategy of making the problem or the anxiety vivid and emotionally charged are not easily achieved through the didactic dimension alone, but rather through hybridization with the two dimensions described below.

It is not often that $\mathrm{TV} /$ video spot advertizing has a context where the strategy is truly relevant, new and interesting information (Schmitt, 1999; McQuarrie and Philips, 2008). However, the didactic experience is expected to be positively related to liking as the information ideally should be experienced as new, interesting, relevant and true. Also classic advertizing effectiveness studies have pointed to 'informativeness' as the most important factor in generating ad liking (Aaker and Stayman, 1990).

This leads us to the following hypothesis:

Hypothesis (H1): The didactic experience is positively related to ad liking.
The narrative dimension is an indirect mode of address, performed through actions and dialogue of proxies, with specific aesthetics of narrative sequence and personal identification (Grodal, 1997, 2009; Højbjerg, 2000). The narrative experience is one of being transported and immersed into the story and the implied 'alternative world' (Green and Brock, 2000). Transportation theory claims that transportation is the result of plot, character and the theory centres on identification and vicariously experiencing 'thoughts, goals, emotions and behaviors' of characters in a story (Green et al., 2004, p. 318; Green and Brock, 2000; Busselle and Bilandzic, 2009). The formats related to this dimension are traditionally conceptualized as 'dramas' (Wells, 1988; Deighton et al., 1989; Stern, 1996), but may actually include all types of narrative such as comedy, romance, etc. (e.g., Stern, 1996). Green and Brock's (2000) theory of narrative transportation has already been introduced in advertizing research (e.g., Escalas, 2004, 2007) suggesting that the 'power of narratives' may be central in generating, not only enjoyment and pleasure, but also persuasion (Escalas, 2007). These studies on narrative transportation used print advertizing as stimulus (Escalas, 2004, 2007), even though Esacalas (2004, p. 46) admits that print advertizing probably is "the least likely medium to evoke transportation". It is fair to assume that TV advertizing holds a strong potential for narrative transportation and there is substantial evidence from previous research that warrants the hypothesis that narrative experience is strongly related to ad liking (Escalas, 2004, 2007), consequently:

Hypothesis (H2): Narrative experience is positively related to ad liking.

The experiential dimensions of the proposed conceptual model extend beyond narrative transportation theory, as Green et al. (2004) claim that "non-narratives do not create alternative worlds for individuals to enter" (p. 314). Consequently, narration theory does not elaborate on other nonnarrative dimensions of experience.

The lyrical dimension is non-narrative in structure and in its purest form seems hardly 'an address' at all, but rather a synaesthetic mode of 'poesis', of 'sensing creation' (Frye, 1957; Grodal, 1997). The structuring principle of the lyrical creative execution is based on aligning/contrasting aesthetic elements such as form, color, space, movement or time (editing, fast/slow motion) rather than logical (argumentative) or narrative principles. An example of a classic TV ad with significant lyrical elements is the 2006 Sony Bravia 'Bouncing Balls' by Fallon London: the ad shows 250.000 colored balls bouncing down the sloping streets of San Francisco 
in slow motion to the soft guitar music by Jose Gonzales. The ad ends with the slogan "Color like no other" (quite a generic claim for a LCD TV). No other arguments, story, characters or attributes support the claim in the ad. Anyone who has seen the Bravia ad would know that the words above describing the ad compare very poorly to the actual experience of the ad. The aesthetic complexity in the lyrical experience makes it hard to conceptualize and difficult to relate to a singular, traditional advertizing format. It may be compared to the formats of 'lyric' (Stern and Gallagher, 1991), 'mood' (Coulson, 1989), 'vignette' (Stern, 1994) or the concept of 'resonance' (McQuarrie and Mick, 1992), as these entail an element of lyrical experience. This does not mean that the lyrical dimension is something 'new' only that it is difficult to relate it to specific formats in the conventional typologies of advertizing. Very often, the development of the lyrical appeals would be referred to as 'visual aesthetics', or as 'high production value' by practitioners. However, as with anything else, the lyrical appeal needs careful integration with the strategy, the creative idea, structure, music, plot and other elements to be effective as a marketing tool.

The lyrical dimension is about elements such as the textures, forms, rhythm, soundscapes and visuals, but particularly experienced as syn-aesthetics (Grodal, 2009, p. 255): the interplay, crossover and (paradoxical) lapses in the experiences perceived through several senses and modalities - at the same time. Grodal (2009) claims that visual sequences that are time manipulated have strong lyrical emphasis and goes on to suggest that, in response to lyrical sequences, the brain may be in a 'temporalparietal associative default mode underpinned by saturated feelings' (p. 255). Grodal (2009) also mentions how the use of light can allow manipulations of the presented objects: their textual, tactile, sculptural and other physical features may be highlighted and generate attentional impact.

Why would an advertiser be interested in the lyrical dimension? Because it may generate 'gripping' experiences with high levels of attention and involvement while implicitly communicating the desired associations: '. ..this activates 'lyrical' associative networks in consciousness, in which the objects are linked at feature level (say, roundness)' (Grodal 1997, p. 165).

The lyrical dimension is expected to influence ad liking positively. If the involvement is successful, then, the experience is 'striking', fascinating, positive and pleasurable. This follows the same principles as narrative transportation (also claimed to offer a state of 'flow', e.g., Green and Brock,
2000; Busselle and Bilandzic, 2009). An experience designed as 'lyrical' may, therefore, be either unsuccessful (not experienced as lyrical) or successful and experienced as lyrical and generate pleasure, therefore:

Hypothesis (H3): Lyrical experience is positively related to ad liking.

Hybridization or 'blending' of proposed dimensions of advertizing experience is expected: interplay of dimensions, elements and modalities is inevitable and makes up the resulting integrative experience. It is a very important point of this conceptual model, that although ads are usually dominated by one dimension, the dimensions are not expected to make up discreet categories of advertizing (Højbjerg, 2000; Andersen, 2003). It seems that the narrative mode blends more easily into hybrids, for example, with lyrical 'dream' sequences or 'sales pitch'dialogue where a 'lecture' is combined with 'drama'. This is evident in the structure of many typical formats: for example, through the use of a (narrative) 'slice of life' drama 'encapsulated' in the frame of a (didactic) 'lecture' spot with authoritative, direct address by an 'expert' presenter (Wells, 1988; Deighton et al., 1989). Ferraland Whitelock (2010, p. 133) found more than half of the advertizing studied to be a form of "lecture/drama" combination, which suggests that hybridization is a very widespread phenomenon. Hybridization offers more subtle expressions than 'lecture/drama' combinations. For example, the lyrical dimension may function as focusing attention on rhetorical tropes (McQuarrie and Mick, 1992; Scott, 1994) or narrative elements (the establishing of the scene or characters).

\subsection{Lyrical experience as supporting the} narrative engagement. An overarching narrative structure is quite flexible and may offer narrative experiences at many levels. As Green and Brock formulate it, narrative transportation is 'an integrative melding of attention, imagery and feelings' (2000, p. 701). As explained above, in the literature on narrative transportation, the level of transportation (or 'engagement') is claimed to be based on plot and character identification (Green and Brock, 2000; Busselle and Bilandzic, 2009). These studies of narrative transportation are based on empirical stimulus material of written narratives or feature length films or TV shows with dramatic plots of narrative characters facing traumatic and extreme danger such as struggling firefighters, murder, kidnapping, etc. (Green et al., 2004; Green et al., 2008; Green and Brock, 2000; Busselle and Bilandzic, 2009). It could be hypothesized that, in the context of thirty or sixty seconds of TV advertizing, high levels of character identification 
(hence, transportation) may be more difficult to achieve. Busselle and Bilandzic (2009) identify attentional focus as a dimension that is relevant in supporting narrative engagement. The 'gripping' quality of the lyrical dimension could be a supporting factor in the narrative experience, particularly relevant in comparatively brief advertizing narratives. Thus, the lyrical elements may integrate with the narrative dimension in a way that supports the narrative transportation. The careful, detailed presentation of scenery, objects, light, sound, movement and characters physical presence are elements that, while not driving the plot (being essentially non-narrative, to some extene, superfluous to the story) may still support the narrative transportation and deepen the narrative engagement.

It is, therefore, hypothesized that the lyrical dimension is positively related to the narrative experience:

Hypothesis (H4): The lyrical experience is positively related to the narrative experience.

Figure 1 depicts the suggested structural model and related hypothesis.

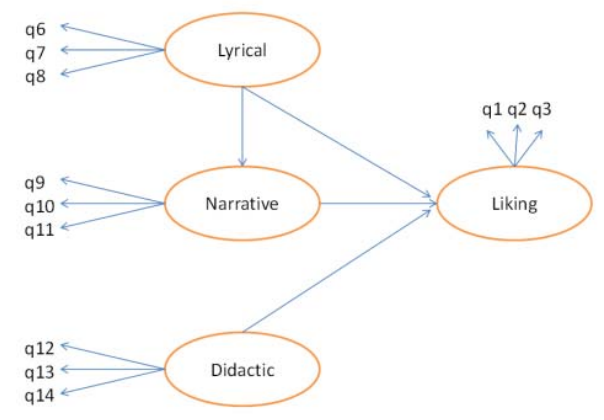

Fig. 1. The structural model

\section{Method}

The chosen dependent variable in this study is Aad. The reasons for choosing this is that Aad is one of the most popular and widely used constructs in research on advertizing (Bergkvist and Rossiter, 2008) and that this variable is considered very reliable and conceptually clear (Bergkvist and Rossiter, 2007, 2008; Muehling and McCann, 1993).

The literature on Aad is both comprehensive and diverse, as can be seen in Muehling and McCann's (1993) review that, already at that time, included more than 100 articles with Aad as a part of the research. Unfortunately, Muehling and McCann's review concluded that "no universal definition of Aad has emerged". Nonetheless, this definition of Aad from Lutz is widely used, often without further discussion: [Aad is...] 'a predisposition to respond in a favorable or unfavorable manner to a particular advertizing stimulus during a particular exposure occasion (MacKenzie and Lutz, 1989).

Aad is considered an affective, global reaction to a particular ad at a specific point in time (Muehling and McCann, 1993). This is a conceptualization that seems to be easily operationalized as ad liking, which Bergkvist and Rossiter (2007) treat as synonymous concepts. Consequently, in the present context and empirical study, we will not differentiate between Aad and ad liking.
2.1. Procedure. Data were collected through two online surveys following a two-step procedure with the first survey being a pilot study aimed at developing and testing multi-item scales for measuring each of the constructs in our conceptual model. The second survey aimed at testing the model and corresponding hypotheses and to demonstrate that the three dimensions are capable of categorizing advertisement executions based on consumers' perception of their degree of didactic, narrative and lyrical experience. Because the aim of this research is developing and testing a theoretical model rather than to conduct application research, student samples were considered appropriate (Calder et al., 1981; Peterson, 2001). The true experiential potential of video spot advertizing was considered extremely difficult to achieve with manipulated or constructed ads, and, therefore, the choice was made to use a carefully selected sample of real TV ads.

2.2. Scale development and pilot study. In the absence of previously validated scales for the three dimensions, the first step in our study was to develop multi-item scales for each of the constructs included in our conceptual model (see Figure 1). Inspired by the literature (e.g., Stern, 1994; Højbjerg, 2000; Andersen, 2003; Green et al., 2004; Grodal, 2009) and supplemented by authors' own suggestions judged to meet face 
validity, five statements were selected for each dimension as candidates for measuring the didactic, narrative and lyrical dimension. It is important to note, that the scales used in this study cannot claim to measure narrative transportation as conceptualized by Green and Brock (2000), as their complex set of scales included scales for measuring the specific narratives and identification with named characters. Also Busselle and Bilanzic argue that Green and Brock's (2000) original theoretical base in concepts of mental imagery invoked by written narratives makes it difficult to transfer their approach to visual media (Busselle and Bilandzic, 2009, p. 322).

Drawing from measures of ad liking in previous studies (e.g., Muehling and McCann, 1993) three items were selected and adapted to the context of this study. With the aim at assessing scale reliability and trimming all scale down to three items, a webbased questionnaire capturing the 18 items and five videos of TV ads were developed and distributed among 32 senior undergraduate students from a media research class in a Danish University. After watching the ads, students were asked to indicate on a 7 -point scale $(1=$ not at all, $7=$ to a very high degree) to what extent they experienced the perceptual 'content' of the 15 statements representing the three experiential dimensions and further, on the same 7-point scale, respond to the three items capturing ad liking. The pilot test produced four three item scales with all constructs exceeding the recommended reliability threshold of .70 (Nunnally, 1978). The final items appearing in each construct are displayed in Table 1 .

Table 1. Selected ads included in the study and their expected dominant experiential dimensions

\begin{tabular}{|l|c|c|c|c|}
\hline & & Didactic & Narrative & Lyric \\
\hline $\begin{array}{l}\text { Advertiser } \\
\text { (brand) }\end{array}$ & Format & & & \\
\hline Expert & Spokesperson & + & & \\
\hline Telia & Product demo/Promotion & + & & \\
\hline Orifarm & Vox pop & + & & \\
\hline Viasat & Product demo/promotion & + & & \\
\hline Tulip & Spokesperson/drama & + & + & \\
\hline DSB & Drama/promotion & + & ++ & \\
\hline Spies & Drama & & ++ & \\
\hline Pepsi & Drama & & ++ & \\
\hline Apollo & Montage & & & ++ \\
\hline SAS & Montage/celebrity & & + & ++ \\
\hline
\end{tabular}

2.3. Final questionnaire and data collection. Following the pilot study, the purified scales were included in the final questionnaire. From a pool of 110 TV spots of which media scheduling and spending were known ten TV spots were selected.

The criteria for selection were the intention of covering a varied and dynamic combination of the three dimensions of perception (see Table 1 for an overview of the selected ads and expected dominant perceptual dimension).

Please note that the theory allows for overlapping categories and hybrid combinations (e.g., lyric and narrative) and that the hypothetical response did not have to match the actual measured response. Care was also taken in selecting advertizing and product categories relevant to the student sample (e.g., soft drinks, OTC drugs, travel). And finally, in order to minimize influence from previous exposures, only ads not being aired during the last six months prior to the study were considered for inclusion in the study.

Around 150 senior undergraduates from a large university were invited to participate in the study. The students were informed about the study in class and subsequently send an email with a link to a survey website where the ten ads were embedded in the questionnaire (in HTML) and shown as streamed video in random sequence and immediately followed by 14 questions on that specific ad experience (mitigating response bias from fatigue and recall error). A total of 55 students ( 23 were male and 32 were female) reported their experiences of all ten selected (response rate 30\%), producing a total of 550 advertizing experiences to be used in our further analysis. Using a student sample is never ideal, but has been widely used in studies of narrative transportation and narrative advertizing (e.g., Green and Brock, 2000; Brusselle and Bilandzic, 2009; Escalas, 2004).

\section{Findings}

Structural equation modelling and cluster analysis were applied in order to first test our suggested framework and next demonstrate its usefulness for categorizing advertizing experiences based on the three dimensions. To accomplish the first part the model in Figure 1 was translated into a SEM model and tested through a two-stage approach (see Anderson and Gerbing, 1988). First, conducting confirmatory factor analysis on the applied multi-item scales we evaluated the measurement model. Next, the measurement model and the structural equation paths were estimated simultaneously to test the proposed model (overall model). With regard to the second part a hierarchical cluster analysis was conducted on the 550 ad perceptions using the three dimensions as clustering variables.

\subsection{Measurement model evaluation.} Confirmatory factor analysis (CFA) was used to evaluate the measurement model. The results of the CFA are shown in Table 2. 
Table 2. Confirmative factor analysis (CFA)

\begin{tabular}{|c|c|c|c|c|c|}
\hline Construct/indicator & $\begin{array}{l}\text { Factor } \\
\text { loading }\end{array}$ & $\begin{array}{l}\text { Standard } \\
\text { error }\end{array}$ & $\mathrm{t}$-value & $\begin{array}{l}\text { Construct } \\
\text { reliability }\end{array}$ & $\begin{array}{l}\text { Extracted } \\
\text { variance }\end{array}$ \\
\hline$\eta 1$ Liking $^{1}$ & & & & .902 & .755 \\
\hline q1: This is a good ad & .929 & --- & & & \\
\hline q2: This ad is definitely not interesting (inv) & .809 & .033 & 26.670 & & \\
\hline $\begin{array}{l}\text { q3: This is an ad one can bear to watch } \\
\text { several times }\end{array}$ & .864 & .031 & 30.860 & & \\
\hline $\begin{array}{l}\eta 2 \text { Didactic }^{2} \\
\text { To what extent did you experience the ad as... }\end{array}$ & & & & .939 & .657 \\
\hline q12: Informative & .946 & --- & & & \\
\hline q13: Presenting relevant information & .847 & .029 & 31.112 & & \\
\hline q14: Enlightening & .948 & .024 & 41.792 & & \\
\hline$\eta 3$ Narrative $^{2}$ & & & & .920 & .790 \\
\hline q9: Telling an engaging story & .844 & --- & & & \\
\hline q10: Entertaining & .909 & .040 & 28.626 & & \\
\hline q11: Dull (inverted) & .911 & .042 & 28.717 & & \\
\hline$\eta 4$ Lyric $^{2}$ & & & & .861 & .677 \\
\hline q6: Poetic & .909 & --- & & & \\
\hline q7: Gripping & .847 & .035 & 27.090 & & \\
\hline q8: Atmospheric & .698 & .035 & 19.496 & & \\
\hline \multicolumn{6}{|c|}{$\chi^{2}(48)=261.922 ; \mathrm{P}=0.000 ; \chi^{2} / \mathrm{DF}=5.457 ; \mathrm{GFI}=0.924 ; \mathrm{CFI}=.965 ; \mathrm{RMSEA}=0.090$} \\
\hline
\end{tabular}

Notes: 1: All items measured on a Likert scale; $1=$ totally disagree, $7=$ disagree. 2 : All items measured on a scale: $1=$ not at all, $7=$ to a very high degree (please note that these scales are translated very directly into English from Danish)

${ }^{\text {a }}$ The first item for each construct was set to 1 .

${ }^{\mathrm{b}}$ Calculated as $\quad \sum(\text { StdLoadings })^{2}$

$\sum(\text { Std. Loadings })^{2}+\sum \xi j$

${ }^{\mathrm{c}}$ Calculated as $\quad \sum$ Std. Loadings ${ }^{2}$

$\sum$ Std. Loadings ${ }^{2}+\sum \xi j$

Although the $\chi^{2}$ statistic was significant $(\chi 2=261,922, \mathrm{df}=48, \mathrm{p}<0.001)$ indicating that the model fails to fit the data in an absolute sense, other indices less vulnerable to sample size points to an acceptable fit (goodness of fit $(\mathrm{GFI})=0.924$; comparative fit $(\mathrm{CFI})=0.965$; root mean square error of approximation $($ RMSEA $)=0.090)$. To conclude, the results indicate a reasonable overall fit between the model and the observed data. Results also support the convergent validity of each of the latent variable. The indicators' regression weights (factor loadings) were all highly significant (t-value $>2.64 ; \mathrm{p}<0.01$ ). Reliability for all the latent constructs was above the recommended lower level of 0.70 (Nunnally, 1978) and all constructs demonstrate an extracted variance above the 0.50 threshold suggested by Fornell and Larcker (1981).

3.2. Structural and model evaluation. Figure 2 depicts the results of the final structural model, including significant standardized path coefficients. Table 3 displays the results of testing the proposed structural model and hypotheses. The fit indices for the structural model suggest that the model has an adequate fit $(\mathrm{GFI}=0.913 ; \mathrm{CFI}=0.958$; RMSEA $=0.097)$.

Hypothesis 1 was concerned with the relationship between didactic experience and liking of the commercials. Although a weak relationship, the hypothesis is supported $(\beta=0.133 ; \mathrm{t}=5.15)$. Results also supported hypothesis 2 providing evidence of a strong positive effect of narrative experience on commercial liking $(\beta=0.853$; $\mathrm{t}=11.38)$. The weak direct relationship between lyrical experience and liking (H3) $(\beta=0.118$; $\mathrm{t}=1.81$ ) shows that lyrical experience dimension only to a limited degree by itself results in more liking. Interestingly, the results support the expected positive relationship between lyrical and narrative experience $(\mathrm{H} 4)(\beta=.802 ; \mathrm{t}=22.30)$. This evidence suggests that the lyrical experience mainly has an indirect positive effect on liking to the extent that it supports the narrative experience $(0.884$ [lyric $\rightarrow$ narrative] x 0.808 [narrative $\rightarrow$ liking $]=0.714)$. 


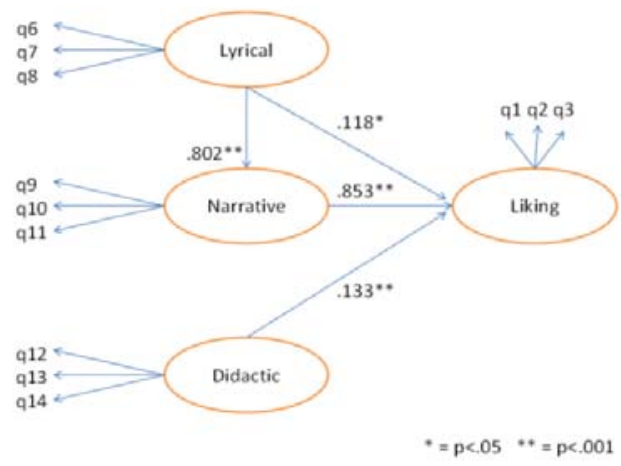

Fig. 2. The Structural model with path coefficients

Table 3. The results of testing the proposed structural model and hypotheses

\begin{tabular}{|l|l|c|c|c|c|}
\hline $\mathrm{H}_{\mathrm{x}}$ & Construct relationships & Estimates & $\begin{array}{c}\text { Std } \\
\text { error }\end{array}$ & $\begin{array}{c}\mathrm{t}- \\
\text { value }\end{array}$ & Hypotheses \\
\hline $\mathrm{H}_{1}$ & Didactic $\rightarrow$ liking & .133 & .026 & $5.15^{* *}$ & Accepted \\
\hline $\mathrm{H}_{2}$ & Narrative $\rightarrow$ liking & .853 & .075 & $11.38^{* *}$ & Accepted \\
\hline $\mathrm{H}_{3}$ & Lyric $\rightarrow$ liking & .118 & .065 & $1.81^{* *}$ & Accepted \\
\hline $\mathrm{H}_{4}$ & Lyric $\rightarrow$ narrative & .802 & .036 & $22.30^{* *}$ & Accepted \\
\hline
\end{tabular}

Notes: $* \mathrm{p}<.05 * * \mathrm{p}<.01$ (1-sided t-test)

The results of the structural model evidence a high degree of predictive power in relation to ad liking as the modelled constructs explain 86 percent of the variance in liking (Table 4). In addition hereto and as already pointed out above, it is interesting to note that that the lyrical dimension explains 78 percent of the variance in the narrative dimension (Table 4).

Table 4. Explained proportion of variance $(n=550)$

\begin{tabular}{|c|c|}
\hline Construct & R2 \\
\hline Liking & .86 \\
\hline Narrative & .78 \\
\hline
\end{tabular}

Note: $\chi^{2}(50)=307.175 ; \quad \mathrm{P}=0.000 ; \quad \chi^{2} / \mathrm{DF}=6.143$; $\mathrm{GFI}=.913 ; \mathrm{NFI}=.950 \mathrm{CFI}=.958 ; \mathrm{RMSEA}=.097$.

3.3. Cluster analysis. In order to further investigate the empirical basis for the proposed framework, a hierarchical cluster analysis was conducted on the 550 ad perceptions using the three summated variables: didactic, narrative and lyric. Distances between the clusters were calculated with the squared Euclidean distance measure, and the aggregation of clusters was performed with Ward's procedure to minimize the within-cluster differences and to maximize the between-cluster differences. Increases in the agglomeration coefficients (indicating the dissimilarity between the clusters to be merged at each clustering stage) were inspected in order to assess the number of clusters. Based on the agglomeration coefficients and interpretation of cluster profiles, a 6 -cluster solution was chosen. The means of the three cluster variables for each cluster are shown in Table 5 along with the results of an ANOVA test.
Table 5. Cluster means and corresponding ANOVA tests

\begin{tabular}{|l|c|c|c|c|c|c|c|}
\hline & $\begin{array}{c}\text { Low } \\
\text { on all }\end{array}$ & $\begin{array}{c}\text { Purely } \\
\text { Didactic }\end{array}$ & $\begin{array}{c}\text { Mainly } \\
\text { Didactic }\end{array}$ & Narrative & $\begin{array}{r}\text { Narrative } \\
\text { Lyric }\end{array}$ & $\begin{array}{c}\text { High } \\
\text { on all }\end{array}$ & $\mathrm{F}(5,544)$ \\
\hline Cluster Size & $10.0 \%$ & $19.3 \%$ & $22.4^{\circ}$ & $12.2^{\circ}$ & $10.7 \%$ & $25.5 \%$ & \\
\hline Didactic & $1.93^{\mathrm{A}}$ & $5.02^{\mathrm{A}}$ & $5.15^{\mathrm{A}}$ & $2.27^{\mathrm{B}}$ & $2.33^{\mathrm{B}}$ & $4.36^{\mathrm{B}}$ & $183.92^{* *}$ \\
\hline Narrative & $2.37^{\mathrm{D}}$ & $1.62^{\mathrm{E}}$ & $3.34^{\mathrm{C}}$ & $6.03^{\mathrm{A}}$ & $4.90^{\mathrm{B}}$ & $6.12^{\mathrm{A}}$ & $426.71^{*}$ \\
\hline Lyric & $2.04^{\mathrm{E}}$ & $1.39^{\mathrm{F}}$ & $2.60^{\mathrm{D}}$ & $3.81^{\mathrm{C}}$ & $5.96^{\mathrm{A}}$ & $5.00^{\mathrm{B}}$ & $376.87^{*}$ \\
\hline Liking & $2.96^{\mathrm{C}}$ & $2.98^{\mathrm{C}}$ & $420^{\mathrm{B}}$ & $5.94^{\mathrm{A}}$ & $5.67^{\mathrm{A}}$ & $6.21^{\mathrm{A}}$ & $151.42^{* *}$ \\
\hline
\end{tabular}

Significant differences were found between clusters across the three clustering variables. An inspection of the last row show that the ads that are perceived as low on all dimensions and the purely didactic ads are the least liked ads, whereas ads that are experienced as higher in the lyrical and/or narrative dimension are also the most liked. The clusters seem to confirm that the framework suggests meaningful and distinct categories of advertizing.

\section{Discussion and managerial implications}

This paper has presented two contributions to advertizing research: an integrative framework of narrative and non-narrative dimensions of advertizing experiences, and while doing this, pointing to the importance of the lyrical dimension.

The framework emphasizes the concept of experience as a concept that is 'integrative' as also narrative transportation is theorized to be (Green and Brock, 2000; Green et al., 2004). Despite the complex and elusive nature of experiences, the study showed that the dimensions are meaningfully distinct and measurable through quantitative scales, and in addition how they interrelated as the concept of hybridization suggests.

An important finding is that the lyrical and narrative dimensions interrelate to support the ad liking. This finding extends the theory on narrative transportation (Green and Brock, 2000; Green et al., 2004; Escalas, 2004, 2007; Busselle and Bilandzic, 2009) which did not include lyrical or other nonnarrative aspects of the narrative experience. 
The presented framework offers a pragmatic approach to measuring the experiential potential video spot advertizing. There are few studies modelling narrative and non-narrative experiential dimensions in TV advertizing, and this study points to the important interplay of experiential dimensions. While the empirical scope of this study is limited, it does show that pragmatic methods for measuring the experiential potential of $\mathrm{TV}$ advertizing for use in tracking or testing can be developed from the conceptual model. Advertisers could use this information as a benchmark within their product category and choice of format/creative strategy.

In advertizing research, the suggested conceptual model and approach may offer a more integrative perspective on the advertizing. For example, in a study comparing global and national brand advertizing such as Ferrall and Whitelock (2001), the experiential potential of global vs. national brand advertizing could be compared. This would yield information on the experiential potential of global vs. national brand advertizing instead of just descriptive characteristics (e.g., 'number of camera shots' or 'frequency of formats').

The conceptual foundation in cognitive film psychology and genre criticism further suggests that qualitative analysis and studies of micro-elements (e.g., McQuarrie and Philips, 2008; Mick et al., 2004; Scott, 1994) is also a potential direction for further research into didactic, narrative and lyrical experiences as important contexts of understanding the appropriate use of micro-elements.

In the current media context, many consumers are ready to skip or block advertizing they find annoying, and advertisers need to consider experiential quality and immediate involvement in the communication as an important part of the communication strategy (Teixeira, 2012). The recent development towards online advertizing has potential to develop strategies with longer formats than the 30-60 second spots conventionally used in broadcast and cable TV, allowing for more effective narrative engagement through character identification and plot. However, the most pertinent challenge for advertisers is using on-line pre-roll advertizing (e.g., on YouTube and remediated in other social media). The challenge is to ensure that the ad is 'gripping' and involving already within the first 5-10 seconds, avoiding viewers clicking the "skip ad" button (an extreme contrast to the long exposure common in narrative transportation studies - e.g., Busselle and Bilandzic, 2009). On the strengths and weaknesses of film vs. print, Green et al. (2008) write 'Print allows an in-depth exploration of character thoughts and feelings that may not work well on the screen. Film viewers may have to compensate by filling in those thoughts and feelings from observed expressions and behaviors. On the other hand, film can provide visual effects that may be far more striking for most individuals than mere words on a page would be' (p. 534: emphasis not in source).

\section{Limitations and directions for future research}

This initial study suggests that future research into the lyrical dimension of advertizing seems warranted. It is important to note that the scales presented in Table 2 were translated from Danish. The 'lyrical' dimension is, by definition, a very subtle experience that is difficult to translate. Further research is necessary to test the scales across linguistic and cultural contexts.

From previous studies, it is shown that student samples may have a potential bias towards stronger relations/coefficients in structural modelling than less homogenous samples, which should be taken into account when evaluating the results. Another issue is the self-selecting nature of the respondents, which may also contribute to the bias. However, one may consider the alternatives: if the measured experiences were the result of, for example, forced (lab) exposure to advertizing in return for course credits (e.g. Green and Brock, 2000; Green et al., 2008) or other rewards could also have influenced the experience of the respondents.

That the advertizing was 'real' and with existing brands, while adding realism and executional quality, was also a limitation. This limitation also made it more difficult to include measures such as purchase intention or brand attitude in the study, as there would be problems with these measures in using pre-existing brands and campaigns.

It needs to be taken into consideration that if advertisers use informational advertizing, ad liking is rarely an objective (Rossiter and Percy, 1996). If the suggested framework was to be used in pragmatic contexts for pre-testing or tracking, this should be as benchmarking within product categories or with careful consideration of communication objectives.

As the sample of advertizing stimuli consisted of $10 \mathrm{TV}$ spots, we do not make general conclusions on the expected level of ad liking of specific dimensions (or hybrids). Further studies with larger samples of ads and respondents are necessary to show the general stability of the clusters and dimensions presented in this initial and limited study. 


\section{References}

1. Aaker, D.A. and Carman, J.M. (1982). Are You Over-Advertizing, Journal of Advertising Research, 22 (4), pp. 57-70.

2. Aaker and Stayman. (1990). Measuring Audience Perceptions of Commercials and Relating Them to Ad Impact, Journal of Advertising Research, 30 (4), pp. 7-17.

3. Andersen, L.P. (2003). Conceptualising Television Advertising: From 'content' to genre, from USP to ISP. In Branding and Advertising, edited by Flemming Hansen and Lars Bech Christensen. Copenhagen: CBS press.

4. Anderson, J.C. and Gerbing, D.W. (1988). Structural equation modeling in practice: a review and recommended two step approach, Psychological Bulletin, 103 (3), pp. 411-423.

5. Batra, R. and Ray, M.L. (1986) Affective responses mediating acceptance of advertising, Journal of Consumer Research, 13 (2), pp. 234-249.

6. Bergkvist, L. and Rossiter, J.R. (2007). The predictive validity of multiple-item versus single-item measures of the same constructs, Journal of Marketing Research, 44 (2), pp. 175-184.

7. Bergkvist L., and Rossiter, J.R. (2008). The role of ad likability in predicting an ad's campaign performance, Journal of Advertising, 37 (2), pp. 85-98.

8. Calder, B.J., Phillips L.W. and Tybout, A.M. (1981). Designing research for application, Journal of Consumer Research, 8 (2), pp. 197-207.

9. Coulson, J.S. (1989). An Investigation of Mood Commercials. In Cognitive and Affective Responses to Advertising, edited by Cafferata, P and Tybout, M.A. Lexington, Mass.: Lexington Books.

10. Deighton, J., Romer, D. and McQueen, J. (1989). Using Drama to Persuade, Journal of Consumer Research, 16 (3), pp. 335-343.

11. Escalas, J.E. (2004). Imagine Yourself In The Product: Mental Stimulation, Narrative Transportation, and Persuasion, Journal of Advertising, 33 (2), pp. 37-48.

12. Escalas, J.E. (2007). Self-Referencing amd Persuasion: Narrative Transformation versus Analytical Elaboration, Journal of Consumer Research, 33 (4), pp. 421-429.

13. Ferral, N. and Whitelock, J. (2010). A comparative analysis of advertising characterestics, strategy, style and form in global and national brand advertising, Journal of Marketing Communications, 7 (3), pp. 125-136.

14. Fornell, C. and Larcker, D.F. (1981). Evaluating structural equation models with unobservable variables and measurement error, Journal of Marketing Research, 18 (1), pp. 39-50.

15. Frye, N. (1957). Anatomy of Criticism: Four Essays. Princeton: Princeton University Press.

16. Green, M.C. and Brock, T.C. (2000). The Role of Transportation in the Persuasiveness of Public Narratives, Journal of Personality and Social Psychology, 79 (5), pp. 701-721.

17. Green, M.C., Brock, T.C. and Kaufman, G.F. (2004). Understanding Media Enjoyment: The Role of Transportation Into Narrative Worlds, Communication Theory, 14 (4), pp. 311-327.

18. Green, M.C., Kass, S., Carrey, J., Herzig, B., Feeny, R. and Sabini, J. (2008). Transportation Across Media: Repeated Exposure to Print and Film, Media Psychology 11 (4), pp. 512-539.

19. Grodal, T. (1997). Moving Pictures, A New Theory of Film Genres, Feelings, and Cognition. Oxford: Clarendon Press.

20. Grodal, T. (2009). Embodied Visions: Evolution, Emotion, Culture and Film. Oxford: Oxford University Press.

21. Haley, R.I. and Baldinger, A.L. (1991). The ARF [Advertising Research Foundation] Copy Research Validity Project, Journal of Advertising Research, 31 (April/May), pp. 11-32.

22. Højbjerg, L. (2000). Fortalleteori 2. Copenhagen: AkademiskForlag.

23. McQuarrie, E.F., and Mick, D.G. (1992). On resonance: A critical pluralistic inquiry into advertising rhetoric. Journal of Consumer Research, 19 (2), pp. 180-197.

24. McQuarrie, E.F. and Phillips, B. J. (2008). Advertising rhetoric: An introduction. In Go Figure! New Directions in Advertising Rhetoric, edited by E. F. McQuarrie and B. J. Phillips. M.E. Sharpe, pp. 3-22.

25. MacKenzie, S.B. and Lutz, R.J. (1989). An Empirical Examination of the Structural Antecedents of Attitude Toward the Ad in an Advertising Pretesting Context, Journal of Marketing, 53 (April), pp. 48-65.

26. Mick, D.G., Burroughs, J.E., Hetzel, P. and Brannen, M.Y. (2004). Pursuing the meaning of meaning in the commercial world: An international review of marketing and consumer research founded on semiotics, Semiotica, $152(1 / 4)$, pp. 1-74.

27. Muehling, D.D., and McCann, M. (1993). Attitude toward the ad: A review. Journal of Current Issues and Research in Advertising, 15 (2), pp. 25-58.

28. Nunnally, J.C. (1978). Psychometric Theory. New York: McGraw-Hill.

29. Peterson, R.A. (2001). On the use of college student in social science Research: Insights from a second-order meta-analysis, Journal of Consumer Research, 23, pp. 450-461.

30. Rossiter, J.R. and L. Percy (1996). Advertising Communications \& Promotion Management. New York: McGrawHill.

31. Scott, L.M. (1994). Images in advertising: The need for a theory of visual rhetoric, Journal of consumer research, 21(2), pp. 252-273.

32. Schmitt, B. (1999). Experiential marketing, Journal of marketing management, 15 (1-3), pp. 53-67.

33. Stern, B.B. (1994). Classical and Vignette Television Advertising Dramas: Structural Models, Formal Analysis, and Consumer Effects, Journal of Consumer Research, 20 (March), pp. 601-615. 
34. Stern, B.B. (1996). Advertising comedy in electronic drama, The construct, theory and taxonomy, European Journal of Marketing, 30 (9), pp. 37-59.

35. Stern, B.B. and Gallagher, K. (1991). Advertising Form, Content, and Values: Lyric, Ballad, and Epic, in Current Issues and Research in Advertising, J.H. Leigh and C.R. Martin, eds. Michigan: University of Michigan.

36. Teixeira, T. (2012). The new science of viral ads, Harvard Business Review, 90 (3), pp. 25-27.

37. Van den Putte, B. (2009). What matters most in advertising campaigns? The relative effect of media expenditure and message content strategy, International Journal of Advertising, 28 (4), pp. 669-690.

38. Vakratsas, D. and Ambler, T. (1999). How advertising works: what do we really know? The Journal of Marketing, 63 (1), pp. 26-43.

39. Wells, W.D. (1988). Lectures and Dramas. In Cognitive and Affective Responses to Advertising, edited by P. Cafferata and A.M. Tybout. Lexington, Mass.: Lexington Books. 